\title{
Spatiotemporal Variations of Extreme Precipitation Events in the Jinsha River Basin, Southwestern China
}

\author{
Dan Zhang, ${ }^{1,2}$ Wensheng Wang $\mathbb{D D}^{1,2}$ Shuqi Liang, ${ }^{1,2}$ and Shunjiu Wang ${ }^{3}$ \\ ${ }^{1}$ School of Water Resource and Hydropower, Sichuan University, 610065 Chengdu, China \\ ${ }^{2}$ State Key Laboratory of Hydraulics and Mountain River Engineering, Sichuan University, 610065 Chengdu, China \\ ${ }^{3}$ Chengdu Institute of Plateau Meteorology, China Meteorological Administration, 610072 Chengdu, China
}

Correspondence should be addressed to Wensheng Wang; wangws70@scu.edu.cn

Received 16 December 2019; Revised 23 March 2020; Accepted 20 September 2020; Published 14 October 2020

Academic Editor: Roberto Fraile

Copyright ( 2020 Dan Zhang et al. This is an open access article distributed under the Creative Commons Attribution License, which permits unrestricted use, distribution, and reproduction in any medium, provided the original work is properly cited.

\begin{abstract}
Climate extremes have attracted widespread attention for their threats to the natural environment and human society. Based on gauged daily precipitation from 1963 to 2016 in four subregions of the Jinsha River Basin (JRB), four extreme precipitation indices developed by the Expert Team on Climate Change Detection and Indices (ETCCDI) were employed to assess the spatiotemporal variations of extreme precipitation events. Results show the following: (1) Max one-day precipitation amount (RX1day), max consecutive five-day precipitation amount (RX5day), precipitation on very wet days (R95p), and number of heavy precipitation days $(\mathrm{R} 10 \mathrm{~mm})$ showed increasing trends in four subregions except for the decline of R10 mm in the southeastern and RX5day in the midsouthern. Extreme precipitation has become more intense and frequent in most parts of the JRB. (2) In space, the four extreme precipitation indices increased from the northwest to the southeast. Temporal trends of extreme precipitation showed great spatial variability. It is notable that extreme precipitation increased apparently in higher elevation areas. (3) The abrupt change of extreme precipitation in the northwestern, midsouthern, and southeastern mainly appeared in the late 1990s and the 2000s. For the midnorthern, abrupt change mainly occurred in the late 1980s. This study is meaningful for regional climate change acquaintance and disaster prevention in the JRB.
\end{abstract}

\section{Introduction}

Extreme precipitation events are important indicators to measure intensity and frequency of precipitation which are very sensitive to climate change [1]. Global warming, increasing atmospheric moisture content, and surface evapotranspiration accelerate the water cycle and enhance extreme precipitation events [2-6]. It is very important for the ecological environment, the lives and property of people, and the national economy to understand the changing law of extreme precipitation events [7-9]. The occurrence of extreme precipitation may cause disaster for the people in a region. In recent years, the occurrence of quite a few extreme precipitation events in China has caused serious casualties and property losses. For example, in 1998, the extreme floods in the Yangtze River basin caused by extreme precipitation events claimed thousands of lives and caused billions of CNY in economic loss. On June 24, 2017, a catastrophic landslide destroyed the Xinmo village in Sichuan province under the influence of prolonged extreme precipitation, and 83 deaths were attributed to this landslide activity $[10,11]$.

Global extreme precipitation had a wetter tendency throughout the 20th century [12]. Griffiths and Bradley found increased precipitation extremes in North America during 1926-2000 [13]. Extreme precipitation events presented great regional differences in South America due to the influence of large scale events [6]. In Asia, extreme daily precipitation events increased in both frequency and intensity in the Philippines during 1951-2010 [14]. Over the past three decades, precipitation showed a downward trend across India [15], but extreme precipitation events increased in some regions $[16,17]$. Almazroui and Saeed found that the accumulation of simulated precipitation related to extreme events 
(RR $>$ 99th percentile) had an increasing trend and the contribution of extreme precipitation events to the accumulated rainfall enhanced over the Arabian Peninsula [18]. Similar to the global trend, extreme precipitation events in China are increasing and have great regional differences [19-24]. It is necessary to investigate the spatial and temporal variations of extreme precipitation events at regional scale.

As the uppermost part of the Yangtze River Basin, the Jinsha River Basin (JRB) is characterized by complex terrain, fragile ecosystems, and underdevelopment [25]. This region is an important zone for water resources and hydropower development, while climatic variability has greatly influenced the socioeconomic development and ecosystem [26-29]. Previous studies observed that precipitation in this region is distributed unevenly in both the spatial and temporal scale. Wang et al. found that the precipitation in the JRB increased slightly and insignificantly and the temperature showed a tendency to warmer [30-32]. An increase trend of continuous multiday extreme precipitation was found under 20- and 50-year return period over the JRB by the GCMs during 2020-2050 [27]. Nevertheless, most of previous studies only focus on annual and seasonal characteristics of precipitation in the JRB and regional extreme precipitation changes in the Yangtze River basin $[33,34]$; few studies have regarded the entirety of JRB as an investigated area to comprehensively analyze the spatiotemporal variations of extreme precipitation events.

This study investigated the spatiotemporal variations of extreme precipitation events in the JRB based on daily precipitation during 1963-2016 and provided a detailed assessment of observed extreme precipitation. Such a study will contribute to providing a scientific reference for reducing the risk of disaster in the JRB and regional responses of precipitation extremes to global climate change. The remainder of this paper is structured as follows: the study area and daily precipitation data are described in Section 2; Section 3 presents analysis techniques and methods; obtained results are presented in Section 4; the discussion and conclusions are given in Section 5.

\section{Study Area and Data}

2.1. Study Area. The Jinsha River Basin (JRB, $24^{\circ} 36^{\prime} \mathrm{N}-$ $\left.35^{\circ} 44^{\prime} \mathrm{N}, 90^{\circ} 30^{\prime} \mathrm{E}-105^{\circ} 15^{\prime} \mathrm{E}\right)$, the uppermost part of the Yangtze River Basin, is located in southwestern China (Figure 1). It has a watershed of $4.7 \times 10^{5} \mathrm{~km}^{2}$ and mountains cover the majority of the basin. The river course crosses Qinghai, Yunnan, Sichuan Province, and Tibet Autonomous Region. The JRB is mainly covered by the Qinghai-Tibet Plateau, the Yunnan-Guizhou Plateau, and the Sichuan Basin. The elevation increases from about $249 \mathrm{~m}$ in the southeast to $6575 \mathrm{~m}$ in the northwest. The JRB encompasses diverse climate patterns, including many types of monsoons and a typical plateau climate. The spatiotemporal variations of precipitation present unique regional characteristics due to the great differences in local altitude and climate conditions.

2.2. Data and Indices of Extreme Precipitation Events. The daily precipitation data of 24 gauged stations within the JRB from 1963 to 2016 was provided by China Meteorological Data Service Center managed by National Meteorological Information Center (http://data.cma.cn/). The data had been subjected to quality control procedures of the China $\mathrm{Me}$ teorological Data Service Center. The linear regression method was used to interpolate values for the little missing data from adjacent stations. Some information on meteorological stations is listed in Table 1. Meteorological stations are distributed over the basin as shown in Figure 1 and can describe precipitation characteristics in space. Subregional average precipitation data was obtained by the arithmetic mean method. The precipitation time series spanning 54 years (1963-2016) at 24 stations are long enough to draw conclusions from a statistical point of view. The 90 -meter resolution Digital Elevation Model data was downloaded from the Geospatial Data Cloud of China and accessed via http://www.gscloud.cn/.

A set of climate indices recommended and developed by the Expert Team on Climate Change Detection and Indices (ETCCDI, http://etccdi.pacificclimate.org/indices.shtml) has been widely used to investigate characteristics and changes in climate [35-39]. Four indices were employed to comprehensively analyze extreme precipitation events in this study (Table 2). Max one-day precipitation amount (RX1day) and max consecutive five-day precipitation amount (RX5day) were two important indicators for flood producing [40]. Precipitation on very wet days (R95p) is a percentile-based indicator and accounts for $20-40 \%$ of annual total precipitation in all stations of the JRB. RX1day, RX5day, and R95p were three intensity indicators. Number of heavy precipitation days (R10mm) was selected to analyze the frequency of extreme precipitation.

\section{Methodology}

3.1. Rotated Empirical Orthogonal Function Analysis. Empirical orthogonal function (EOF) analysis is a decomposition of a signal or dataset based on orthogonal basis functions determined from the data. It is an efficient method to split the spatial-temporal field into both space and time and is widely used in the study of meteorology and climatology $[33,41,42]$. The output of the EOF method includes the time coefficient (PCs), spatial pattern (EOFs), eigenvalues, and others. However, the obtained patterns are not physically meaningful due to orthogonality in both space and time. To overcome the limitation of EOF, the VARIMAX method was used to obtain rotated EOFs [43, 44]. Rotated empirical orthogonal function (REOF) relaxes the orthogonality of the spatial patterns and yields localized structures. REOF was good at dividing climatic patterns [45]. In this study, regionalization was obtained by the distribution of loadings.

3.2. Estimation of Tendency. The MK test is a distributionfree rank-based method $[46,47]$ and utilized routinely in trend detection in hydrological and meteorological time series [16, 48, 49]. However, some time series have serial correlation, which may lead to incorrect conclusions for MK tests. Thus, trend free prewhitening MK (TFPW-MK) was 


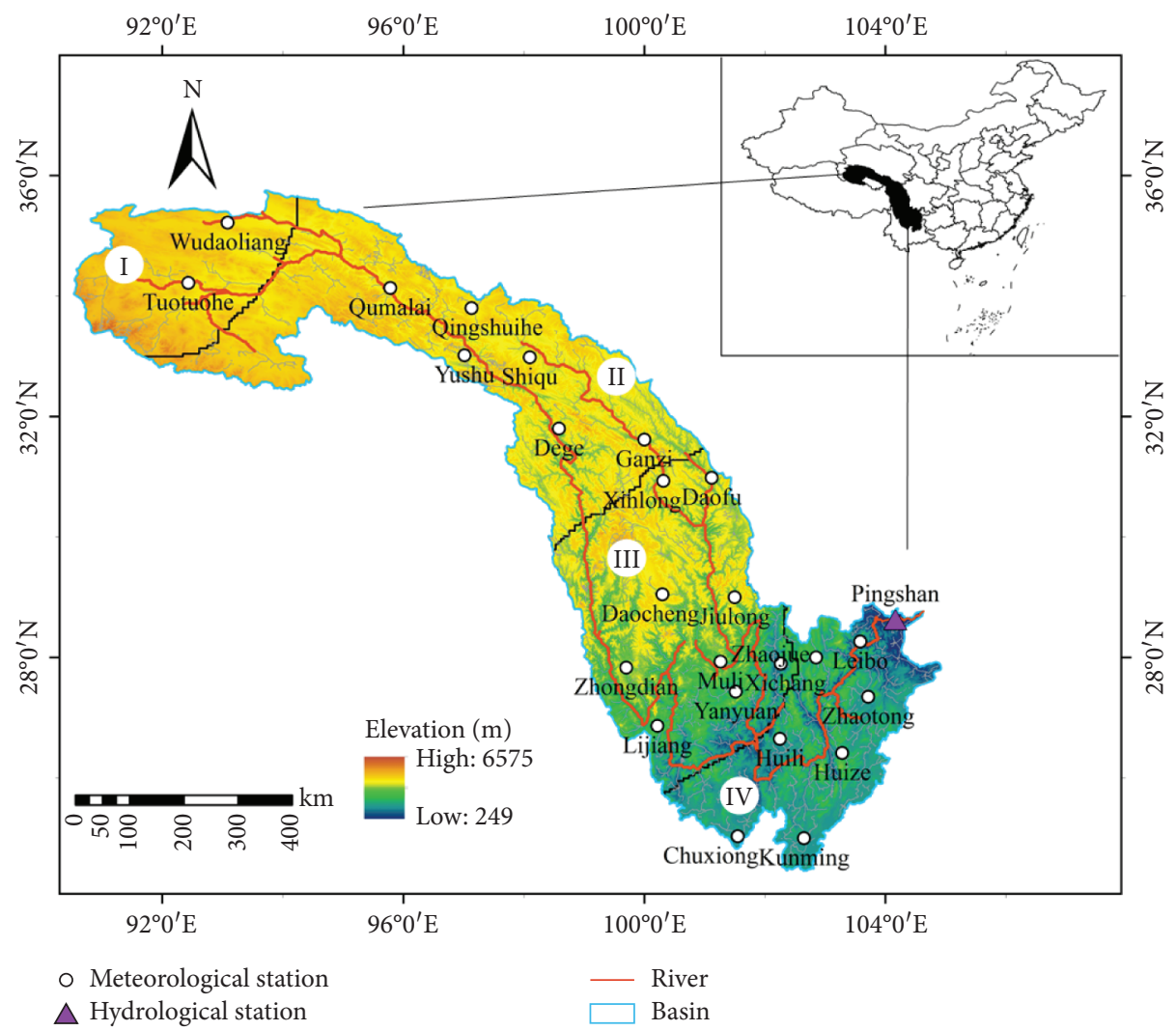

FIgURE 1: Geographical location of the Jinsha River Basin, the distribution of meteorological stations, and four subregions, including the northwestern (I), the midnorthern (II), the midsouthern (III), and the southeastern (IV).

TABLE 1: List of the selected meteorological stations.

\begin{tabular}{lcccccc}
\hline Station code & Station name & Latitude $\left({ }^{\circ} \mathrm{N}\right)$ & Longitude $\left({ }^{\circ} \mathrm{E}\right)$ & Elevation $(\mathrm{m})$ & Data period & Annual average precipitation $(\mathrm{mm})$ \\
\hline 52908 & Wudaoliang & 35.22 & 93.08 & 4612.2 & $1957-2016$ & 291.6 \\
56004 & Tuotuohe & 33.95 & 92.62 & 4533.1 & $1957-2016$ & 291.2 \\
56021 & Qumalai & 34.53 & 95.47 & 4231.2 & $1957-2016$ & 415.5 \\
56029 & Yushu & 33.10 & 96.75 & 3702.6 & $1953-2016$ & 483.3 \\
56034 & Qingshuihe & 33.80 & 97.13 & 4415.4 & $1957-2016$ & 516.3 \\
56038 & Shiqu & 33.23 & 97.73 & 4200 & $1961-2016$ & 573.7 \\
56144 & Dege & 31.83 & 98.63 & 3201.2 & $1957-2016$ & 622.9 \\
56146 & Ganzi & 31.63 & 99.98 & 3393.5 & $1951-2016$ & 648.9 \\
56167 & Daofu & 31.00 & 101.17 & 2957.2 & $1958-2016$ & 606.9 \\
56251 & Xinlong & 30.95 & 100.27 & 3000 & $1960-2016$ & 624.6 \\
56459 & Muli & 28.18 & 100.80 & 2666.6 & $1960-2016$ & 822.1 \\
56357 & Daocheng & 29.05 & 100.18 & 3727.7 & $1957-2016$ & 640.5 \\
56462 & Jiulong & 28.98 & 101.55 & 2987.3 & $1953-2016$ & 910.0 \\
56479 & Zhaojue & 28.23 & 102.95 & 2132.4 & $1957-2016$ & 1032.8 \\
56485 & Leibo & 28.30 & 103.62 & 1474.9 & $1953-2016$ & 857.2 \\
56565 & Yanyuan & 27.45 & 101.62 & 2439.4 & $1957-2016$ & 801.4 \\
56571 & Xichang & 27.88 & 102.30 & 1590.7 & $1951-2016$ & 1018.0 \\
56671 & Huili & 26.68 & 102.25 & 1788.4 & $1953-2016$ & 1137.8 \\
56543 & Zhongdian & 27.83 & 99.70 & 3276.1 & $1958-2016$ & 627.2 \\
56586 & Zhaotong & 27.33 & 103.75 & 1949.5 & $1951-2016$ & 705.2 \\
56651 & Lijiang & 26.87 & 100.43 & 2393.2 & $1951-2016$ & 954.9 \\
56684 & Huize & 26.42 & 103.28 & 2109.5 & $1953-2016$ & 794.8 \\
56768 & Chuxiong & 25.02 & 101.53 & 1772.0 & $1953-2016$ & 849.7 \\
56778 & Kunming & 25.03 & 102.68 & 1891.4 & $1951-2016$ & 988.0 \\
\hline
\end{tabular}


TABLE 2: Definitions of extreme precipitation indices.

\begin{tabular}{lcccc}
\hline Type & Index & Definition & Descriptive name & Unit \\
\hline Intensity & RX1day & Annual maximum one-day precipitation & Max one-day precipitation amount & mm \\
Intensity & RX5day & Annual maximum consecutive five-day precipitation & Max five-day precipitation amount & mm \\
Intensity & R95p & Annual total precipitation when $R R>95$ th percentile & Precipitation on very wet days & mm \\
Frequency & R10mm & Annual count of days when RR $\geq 10 \mathrm{~mm}$ & Number of heavy precipitation days & days \\
\hline
\end{tabular}

${ }^{*} \mathrm{RR}$ is daily precipitation.

TABle 3: Pearson correlation coefficients between annual total precipitation and extreme precipitation indices and cross-correlation coefficients between different extreme precipitation indices.

\begin{tabular}{lcccc}
\hline & ATP & RX1day & RX5day & R95p \\
\hline ATP & 1 & & & \\
RX1day & $0.61^{* *}$ & 1 & & \\
RX5day & $0.78^{* *}$ & $0.62^{* *}$ & 1 & 1 \\
R95p & $0.88^{* *}$ & $0.71^{* *}$ & $0.83^{* *}$ & $0.82^{* *}$ \\
R10mm & $0.96^{* *}$ & $0.54^{* *}$ & $0.76^{* *}$ & 1 \\
\hline
\end{tabular}

${ }^{* *}$ Values show a statistically significant correlation at the 0.01 level.

employed to remove correlation $[50,51]$. If there is a linear trend in hydroclimatic time series, the magnitude of the trend can be estimated using nonparametric Sen's slope method [52-54].

3.3. Test Method of Abrupt Change. Extreme precipitation may have strong spatiotemporal heterogeneity; abrupt extreme precipitation change analysis was conducted using three abrupt change test methods including the ordered clustering method (OCM), Pettitt test, and Mann-Kendall mutation test. Detection of abrupt change can helpfully analyze the trend in a time series [55].

3.3.1. Ordered Clustering Method. The ordered clustering method is an effective method to estimate the most likely abrupt point of time series by statistical analysis [56]. The basic idea of this method is to find a time point to divide the time series into two subsequences and to make the sum of deviation squared of the subsequences minimum and the sum of deviation squared between subsequences maximum [57].

3.3.2. Pettitt Test. Pettitt test is a nonparametric method which does not need to consider the distribution type of variables. It is based on the Mann-Whitney two-sample test. This method can detect whether there is a change point and find the location of the change point [58]. If the value of approximate probability, $p$, is less than 0.05 , then the change point is considered statistically significant.

3.3.3. Mann-Kendall Mutation Test. The Mann-Kendall mutation method seems to be an appropriate method for analyzing abrupt change and has been commonly used in time series such as streamflow, precipitation, and water quality. If curves of the two statistics of the Mann-Kendall mutation test $\left(\mathrm{UF}_{k}\right.$ and $\left.\mathrm{UD}_{k}\right)$ have cross points and the points occur within the confidence interval, the cross points can be viewed as significant abrupt change points [59].

\section{Results}

4.1. Precipitation Features and Regionalization. Impacted by monsoon activities and landform, the precipitation in the JRB is unevenly distributed, which gradually increased from the northwest to the southeast. Multiyear average annual precipitation ranged from 293 to $1135 \mathrm{~mm}$ for the 24 stations. A one-way analysis of variance (one-way ANOVA) test was applied to compare the annual total precipitation (ATP) in all stations. The results showed that the difference was significant $(p<0.001)$. The study on regionalization of precipitation and extremes can help to furtherly understand the space differences. To our knowledge, no regionalization study specifically for precipitation in the Jinsha River Basin has been done yet.

Considering the close correlations between extreme precipitation indices and annual total precipitation (Table 3), the EOF and REOF analyses were applied to partition the study area according to the annual total precipitation. The first 7 EOFs together represented $80 \%$ of the total variance, and the first 4 EOFs together represented $68 \%$ of the total variance (Table 4 ). The fact that the first 4 EOFs captured more than $60 \%$ of the total variability indicated that the complexity of the spatial pattern of precipitation over the Jinsha River Basin can largely be explained by a small number of spatial structures. The "scree test" was used to determine the number of significant orthogonal functions [60]. The first four eigenvalues were well separated from the rest. The first four EOFs were retained to be rotated using VARIMAX method. The obtained spatial field was handled by the inverse distance weighting interpolation with the GIS technique. Figure 2 shows the distributions of the field of the first four REOFs for the annual total precipitation in the JRB. Based on distributions of these high loading eigenvectors (the absolute values of the contours equal to or larger than 
TABLE 4: The variance contribution of the first four EOF and REOF modes.

\begin{tabular}{lcccc}
\hline \multirow{2}{*}{ Mode } & \multicolumn{2}{c}{ EOF } & \multicolumn{2}{c}{ REOF } \\
& Explained variance (\%) & Accumulate explained variance (\%) & Explained variance (\%) & Accumulate explained variance (\%) \\
\hline 1 & 39.3 & 39.3 & 22.4 & 22.4 \\
2 & 14.9 & 54.3 & 9.8 & 32.2 \\
3 & 8.0 & 62.2 & 22.5 & 54.7 \\
4 & 5.8 & 68.1 & 13.3 & 68.1 \\
\hline
\end{tabular}

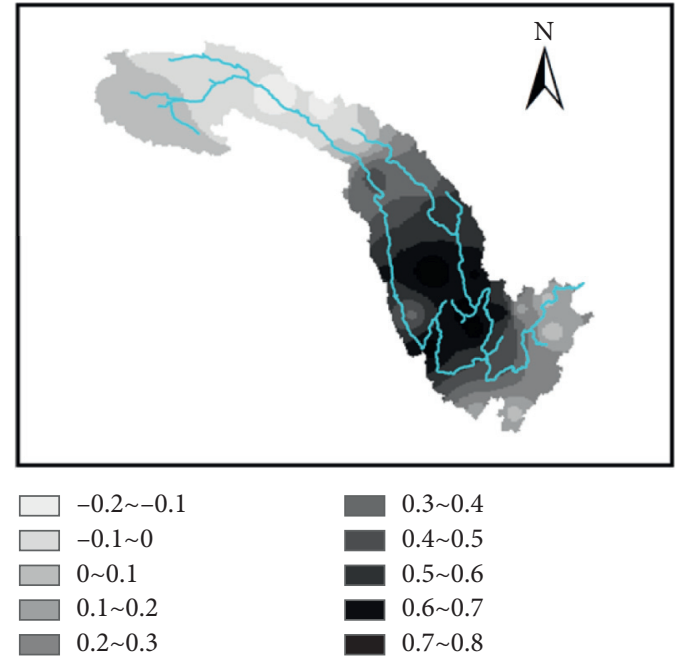

(a)

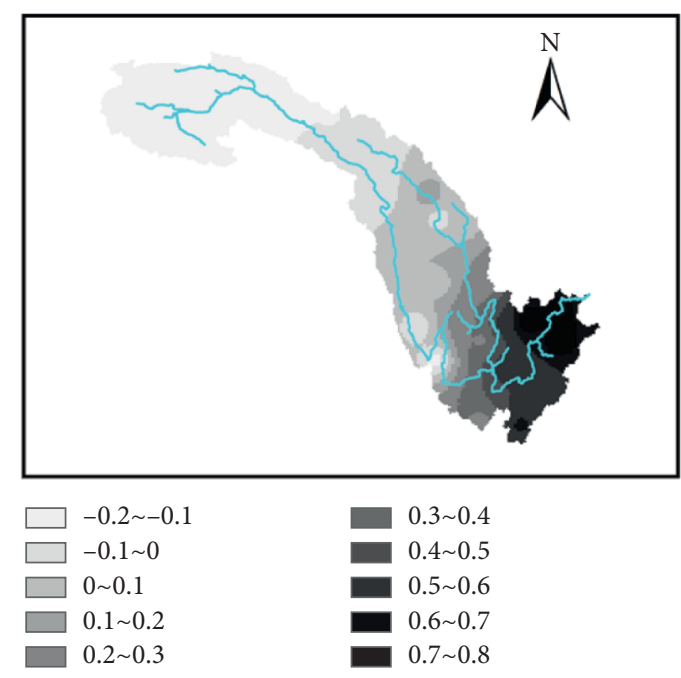

(c)

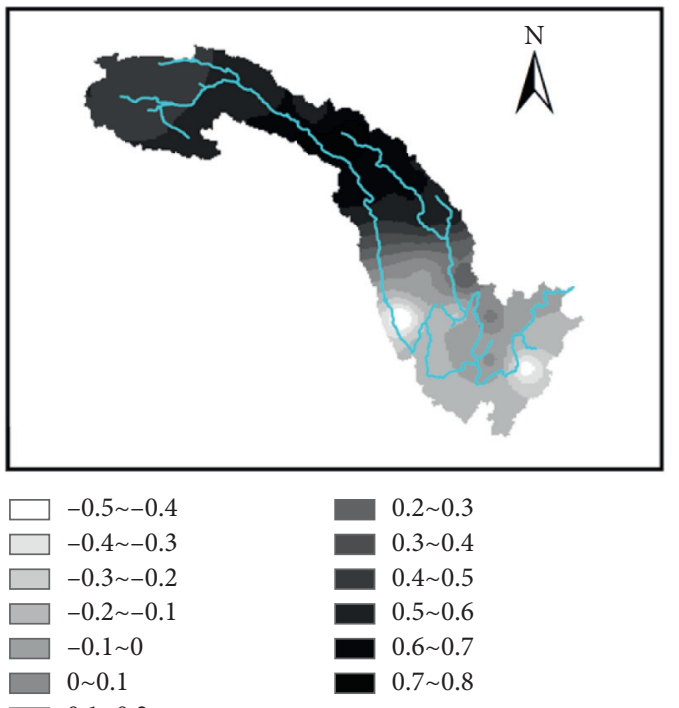

(b)

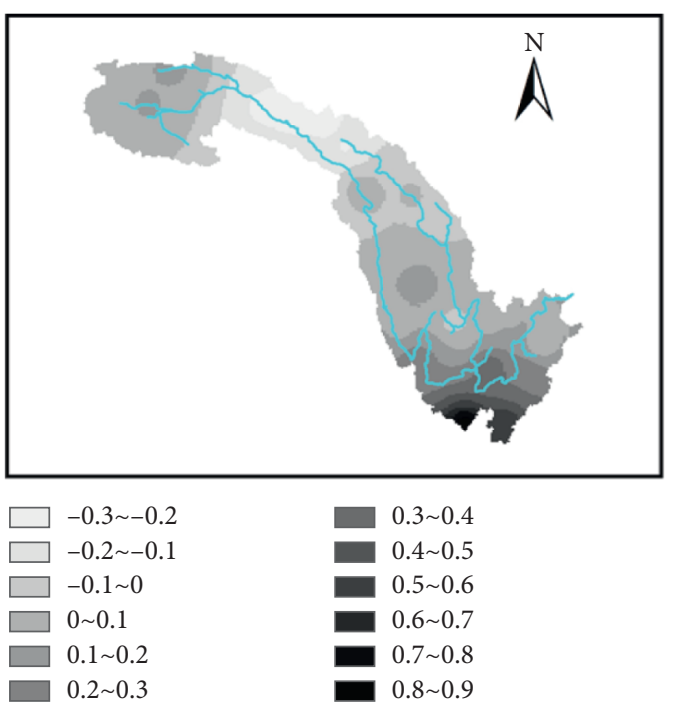

(d)

FIGURE 2: Distribution of the field of the (a) first, (b) second, (c) third, and (d) fourth REOF modes for the annual total precipitation in the JRB.

$0.5)$, four subregions areas for variations of precipitation in the JRB were identified (Figure 1).

4.2. Temporal Variation of Extreme Precipitation Events. The temporal variations of extreme precipitation indices from the TFPW-MK test and Sen's slope in the four regions are summarized in Table 5. Max one-day precipitation amount (RX1day) and precipitation on very wet days (R95p) increased in all four regions of which RX1day in region IV (the southeastern) and $\mathrm{R} 95 \mathrm{p}$ in region I (the northwestern) reached a significant level $(\alpha=0.05)$. The magnitude of the trend in RX1day increased from the upper basin to the lower 
TABLE 5: Decadal trends of extreme precipitation indices in the four subregions of the JRB.

\begin{tabular}{lcccc}
\hline Subregions & $\begin{array}{c}\text { RX1day } \\
\text { mm/decade }\end{array}$ & $\begin{array}{c}\text { RX5day } \\
\text { mm/decade }\end{array}$ & $\begin{array}{c}\text { R95p } \\
\text { mm/decade }\end{array}$ & $\begin{array}{c}\text { R10mm } \\
\text { d/decade }\end{array}$ \\
\hline I & 0.04 & 0.52 & $7.89^{*}$ & 0.35 \\
II & 0.14 & 0.26 & 5.41 & 0.12 \\
III & 0.65 & -0.74 & 12.73 & 0.22 \\
IV & $1.41^{*}$ & 0.36 & -0.38 \\
\hline
\end{tabular}

*Values show statistically significant trend at the 0.05 level.

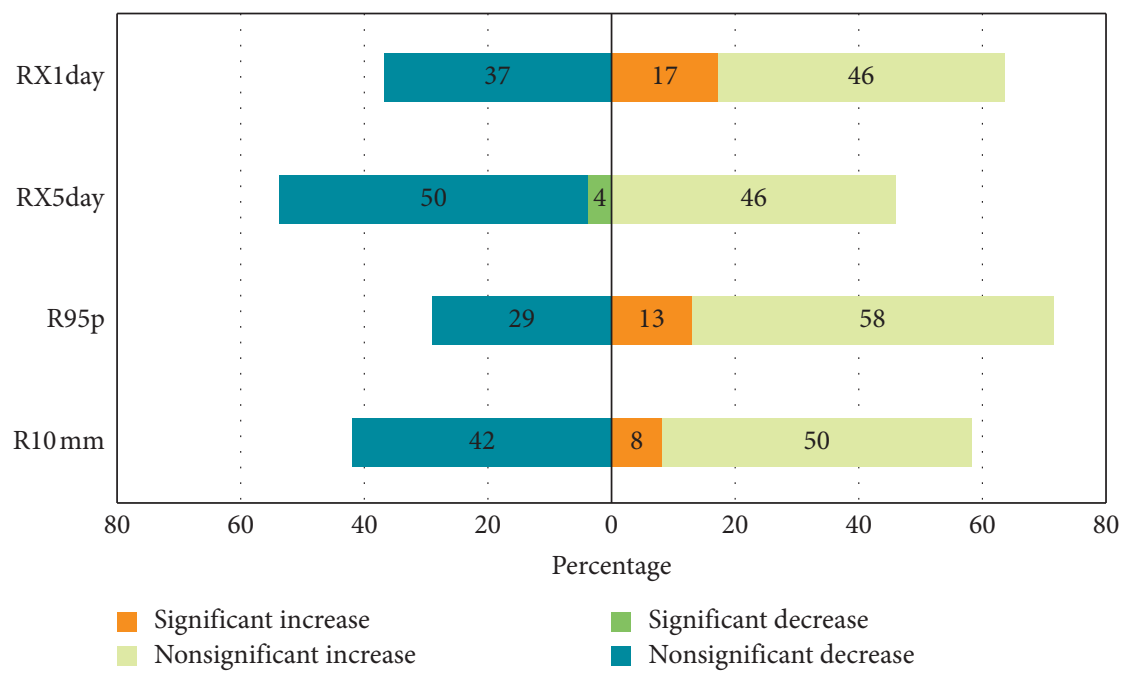

Figure 3: Percentages of stations for each extreme precipitation index that showed increasing and decreasing trends.

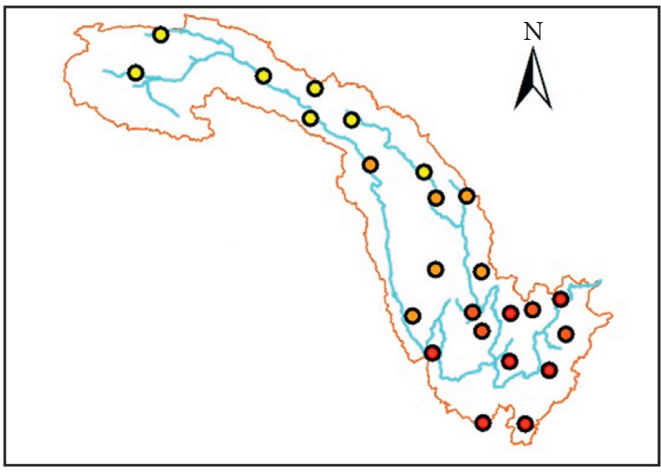

RX1day (mm)

O $20 \sim 28$

○ $28 \sim 44$
- $44 \sim 56$

- $56 \sim 83$

(a)

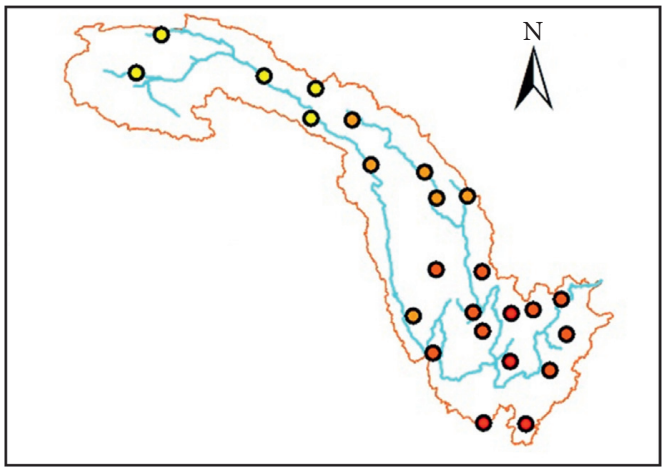

RX5day (mm)

O $42 \sim 55$

○ $55 \sim 81$

- $81 \sim 113$

- $113 \sim 148$

(b)

Figure 4: Continued. 


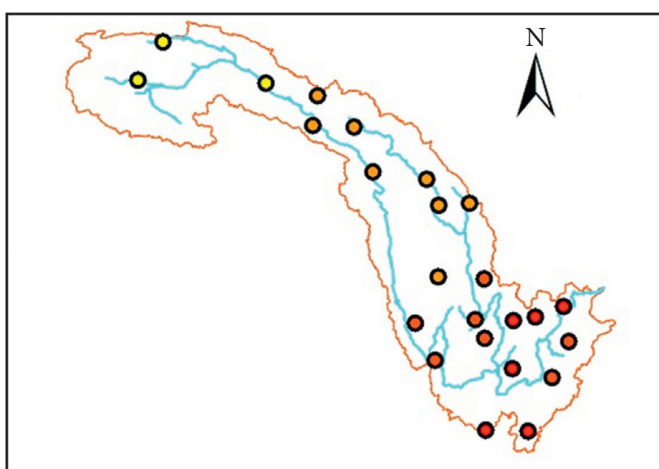

$\mathrm{R} 95 \mathrm{p}(\mathrm{mm})$

○ $79 \sim 117$

○ $117 \sim 173$
○ $173 \sim 264$

○ $264 \sim 350$

(c)

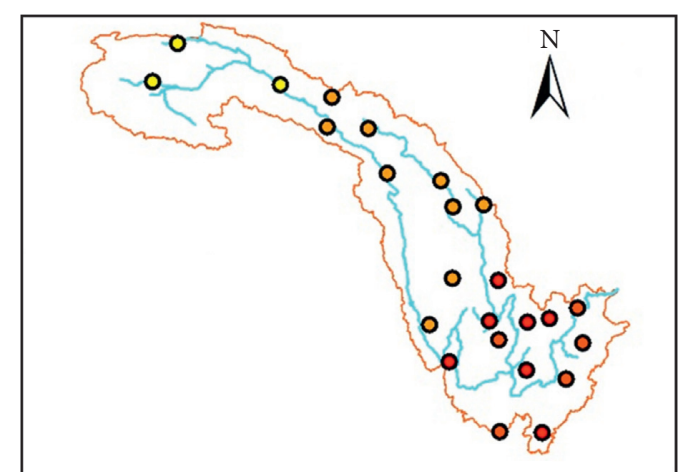

$\mathrm{R} 10 \mathrm{~mm}(\mathrm{~d})$

○ $5 \sim 11$

○ $11 \sim 22$
- $22 \sim 28$

○ $28 \sim 35$

(d)

FIGURE 4: Spatial distributions of extreme precipitation indices in the JRB.

TABLE 6: Mean values of extreme precipitation indices in the four subregions of the JRB.

\begin{tabular}{lcccc}
\hline Subregions & $\begin{array}{c}\text { RX1day } \\
(\mathrm{mm})\end{array}$ & $\begin{array}{c}\text { RX5day } \\
(\mathrm{mm})\end{array}$ & $\begin{array}{c}\text { R95p } \\
(\mathrm{mm})\end{array}$ & $\begin{array}{c}\text { R10mm } \\
(\mathrm{d})\end{array}$ \\
\hline I & 20.9 & 42.8 & 79.9 & 5.7 \\
II & 25.6 & 55.9 & 134.3 & 14.4 \\
III & 43.3 & 89.4 & 203.4 & 25.6 \\
IV & $\mathbf{6 4 . 5}$ & $\mathbf{1 1 1 . 0}$ & $\mathbf{2 8 7 . 8}$ & $\mathbf{2 8 . 2}$ \\
\hline
\end{tabular}

Bold values show the largest mean values.

basin. This may be related to the uneven precipitation in the JRB which increased gradually from the northwest to the southeast. R95p increased much more in regional IV than the other three regions; R95p in region II (the midnorthern) just showed a slightly increasing trend at a rate of $0.35 \mathrm{~mm} /$ decade. Max consecutive five-day precipitation amount (RX5day) increased nonsignificantly in regions I, II, and IV and decreased nonsignificantly in region III (the midsouthern). Number of heavy precipitation days (R10mm) showed increasing trends in regions I, II, and III with slopes of about $0.55,0.12$, and $0.22 \mathrm{~d} /$ decade, respectively, of which region I reached a significant level $(\alpha=0.05)$. Decreasing trend was detected for $\mathrm{R} 10 \mathrm{~mm}$ in region IV.

In addition, percentages of stations that showed increasing and decreasing trends in each extreme precipitation index in the JRB were calculated and plotted in Figure 3. Most of the stations experienced increasing in RX1day, R95p, and R10mm though few trends were statistically significant. About $63 \%$ of stations had increasing trends for RX1day, and this index owned the largest significance as $17 \%$ of stations experienced a significant increase. For R95p, 71\% of stations had increasing trends, but only about $13 \%$ of these trends were statistically significant; $29 \%$ of stations had decreasing trends for R95p. R95p owned the largest percentage of stations which showed increasing trends. $58 \%$ of stations showed increasing trends for R $10 \mathrm{~mm}$ with only $8 \%$ being significant, and $42 \%$ of stations showed decreasing trends in this index. These indicated that extreme precipitation events have become more intense and frequent over the study period. As for RX5day, the percentages of stations which showed increasing trends and decreasing trends were awfully equal.

\subsection{Spatial Variation of Extreme Precipitation Events}

4.3.1. Extreme Precipitation Indices. The spatial distributions of the four indices are illustrated in Figure 4. RX1day, RX5day, R95p, and R10mm shared a similar spatial pattern, gradually increasing from northwest to southeast (Figures 4(a)-4(d)). For instance, the annual values of RX1day varied from 20.4 to $82.0 \mathrm{~mm}$ with lower values in the upper basin and higher values in the lower basin, which was also detected in a previous study [61]. The mean value of each extreme precipitation index in each region was calculated (Table 6). For all four indices, the largest mean values emerged in region IV and the smallest mean values appeared in region I.

4.3.2. Decadal Trends of Extreme Precipitation Indices. The TFPW-MK test and Sen's slope were employed to investigate the spatial variations of each index's changing trend of the individual stations. Figure 5 gives the spatial distributions of decadal trends of extreme precipitation indices over the JRB. About $63 \%$ of the stations exhibited increasing trends in RX1day with four statistically significant stations $(\alpha=0.05)$ in the lower basin (Figure 5(a)). The change trend of RX5day was spatially heterogeneous (Figure 5(b)). There are some regional differences in the spatial distribution of the R95p and R10mm change trends. For R95p, the upper and lower basin 


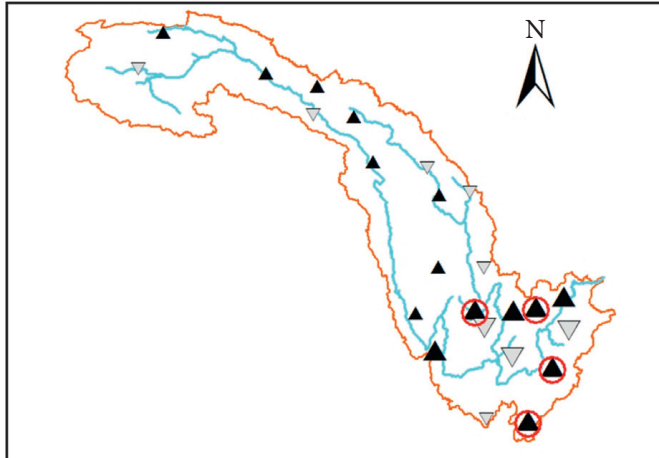

RX1day (mm/decade)

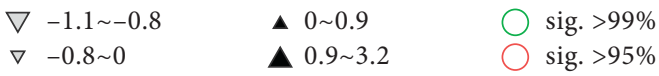

(a)

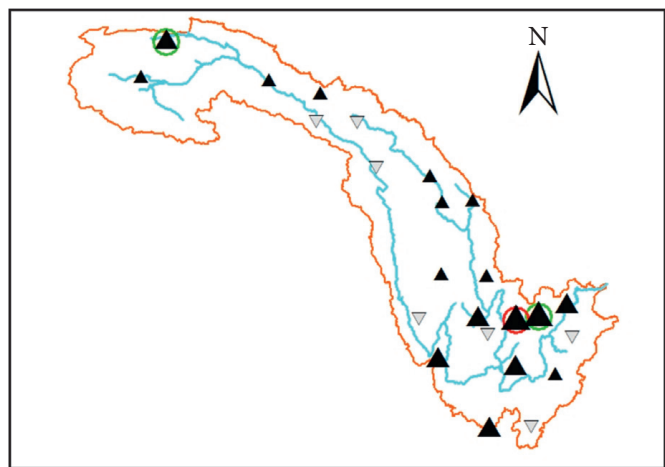

$\mathrm{R} 95 \mathrm{p}$ ( $\mathrm{mm} /$ decade)

$\nabla-5.3 \sim 0$

$\nabla \quad 0 \sim 9$

( $9 \sim 18$

А $18 \sim 27$

sig. $>99 \%$

(c)

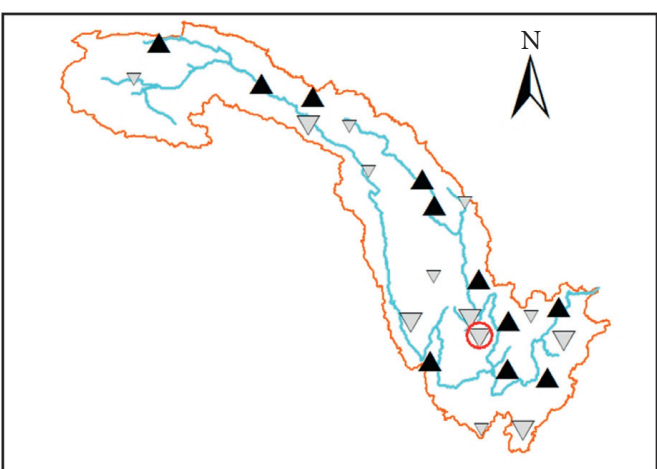

RX5day (mm/decade)
$\nabla-5.1 \sim-1.4$
sig. $>99 \%$
$\nabla-1.4 \sim 0$
sig. $>95 \%$

A $0 \sim 3.8$

(b)

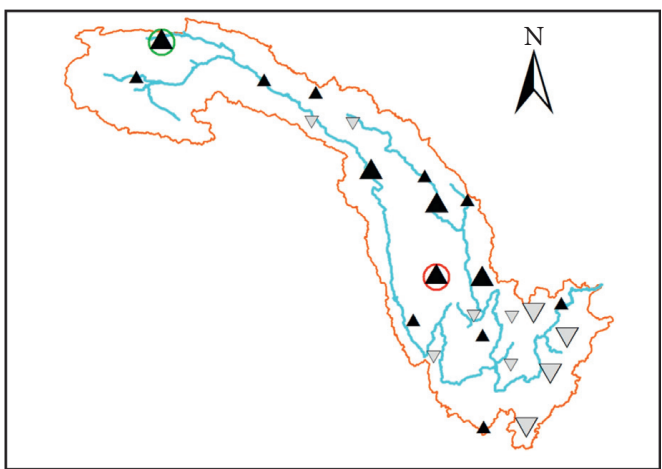

$\mathrm{R} 10 \mathrm{~mm}$ ( $\mathrm{mm} /$ decade)
$\nabla-0.9 \sim-0.6$
A $0 \sim 0.3$
sig. $>99 \%$
$\nabla \quad-0.6 \sim 0$
А $0.3 \sim 1.1$
sig. $>95 \%$

(d)

FIGURE 5: Spatial distributions of decadal trends of extreme precipitation indices in the JRB. Black triangles denote increasing trends; grey triangles denote decreasing trends. Red and green circles represent significance of trends.

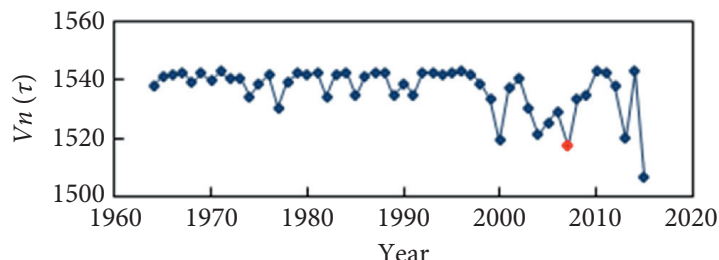

(a)

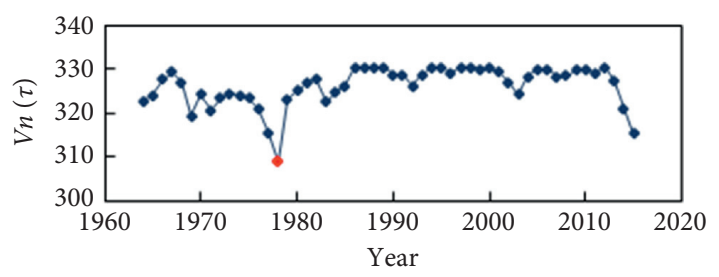

(c)

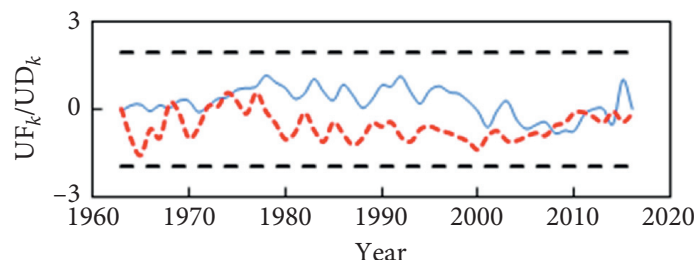

(b)

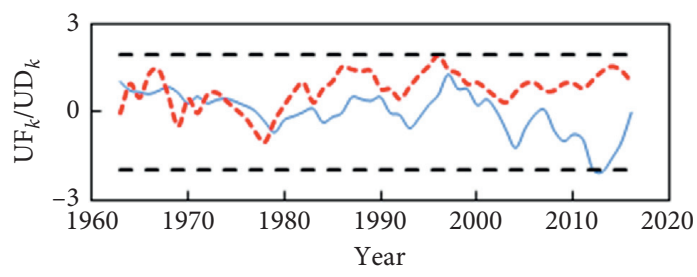

(d)

FIgURE 6: Continued. 


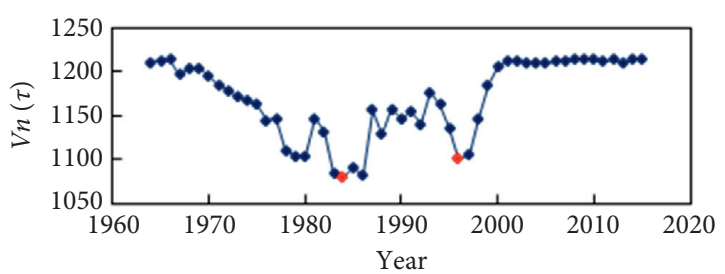

(e)

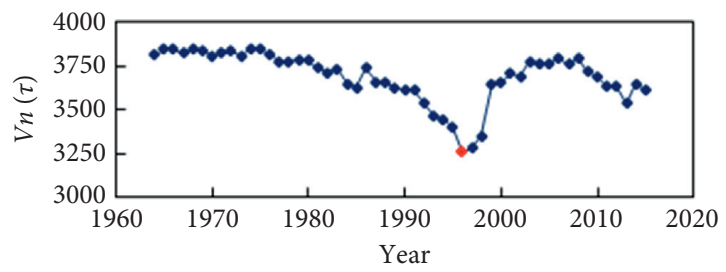

(g)

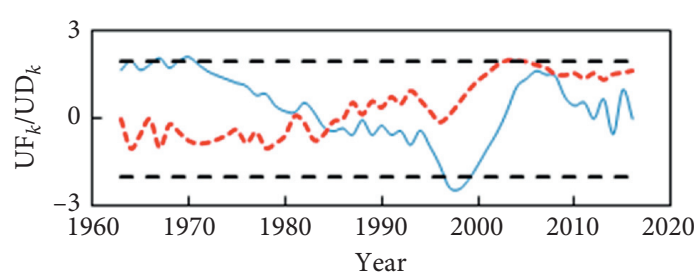

(f)

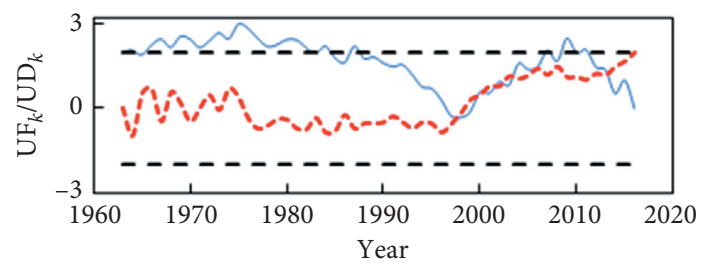

(h)

Figure 6: Abrupt change diagnosed graphs of the ordered clustering method ((a), (c), (e), and (g)) and Mann-Kendall mutation test ((b), (d), (f), and (h)) for max one-day precipitation amount in the four subregions.

TABLE 7: Results of abrupt change analysis.

\begin{tabular}{lcccc}
\hline Index & RX1day & RX5day & R95p & R10mm \\
\hline I & $2007^{*}$ & 2000 & $1998 / 2007^{*}$ & $2007^{* *}$ \\
II & 1978 & 1989 & 1989 & - \\
III & 1984 & 2002 & 1997 & $1986 / 2004$ \\
IV & 1997 & - & 1997 & - \\
\hline$*, * *$
\end{tabular}

*,** Values show statistically significant trend at the 0.05 and 0.01 level.

were dominated by an increasing trend of which three stations were statistically significant (Figure 5(c)). In the middle basin, the number of stations showing increasing trends was almost equal to stations with decreasing trends. For R10mm, the upper and middle basin were dominated by an increasing trend, while the lower basin was dominated by a decreasing trend. In sum, trends of extreme precipitation indices showed great spatial variability across the JRB. Most region of the JRB showed increasing in RX1, R90p, and R10mm.

4.4. Abrupt Change Analysis. Abrupt change analysis of extreme precipitation events was conducted by the ordered clustering analysis, Pettit test, and Mann-Kendall mutation test. Figure 6 shows the diagnosed graphs of the ordered clustering analysis and Mann-Kendall mutation test in RX1day for the four subregions in the JRB. Abrupt change in RX1day in region I was detected in 2007 (Figures 6(a) and $6(\mathrm{~b})$ ). In region $\mathrm{II}$, the increasing turning point of RX1day occurred in 1978 (Figures 6(c) and 6(d)). From Figure 6(e), the most likely change points in 1984 and 1996 were found by the ordered clustering analysis. In Figure 6(f), UF and UD statistic curves had only one intersection in 1984. Although the diagnosis results are different, it is more appropriate to regard 1984 as a point of abrupt change in region III. The increasing turning points of RX1 in region IV occurred in 1997 (Figures 6(g) and 6(h)).
Table 7 shows the results of abrupt change analysis for the time series of extreme precipitation indices in the four subregions. From Table 7, it can be seen that the abrupt change of extreme precipitation indices in region I mainly appeared in 2007. In region II, RX1day abruptly changed in 1978 and RX5day and R95p abruptly changed in 1989; there were no abrupt change points for RX10mm. For region III, abrupt changes of extreme precipitation indices were more likely to occur around 1984, 1997, and 2002. For region IV, RX1day and R95p abruptly changed in 1997; RX5day and R10mm made no abrupt change points in this region.

\section{Discussion and Conclusions}

Humans and natural environment are easily affected by climate extremes. The influence of climate extremes on the society and natural environment is increasing under the global warming background [7, 25, 62, 63]. The Jinsha River Basin is highly sensitive to climate change due to its geographic, ecological, and social background. This study investigated the spatiotemporal variations of four extreme precipitation indices such as max one-day precipitation amount (RX1day), max consecutive five-day precipitation amount (RX5day), precipitation on very wet days (R95p), and number of heavy precipitation days $(\mathrm{R} 10 \mathrm{~mm})$ in the Jinsha River Basin. It would be helpful for evaluating 
changes of extreme precipitation at the regional scale and the management and mitigation of natural hazards.

Based on daily precipitation records from 24 meteorological stations during 1963-2016, the Jinsha River Basin was divided into four subregions using rotated empirical orthogonal function analysis (REOF) and four extreme precipitation indices were selected to analyze the spatiotemporal variations of extreme precipitation events in the Jinsha River Basin in southwestern China. Results indicated that RX1day, RX5day, R95p, and R10mm had increasing trends in four subregions except that $\mathrm{R} 10 \mathrm{~mm}$ decreased in the southeastern (region IV) and RX5day decreased in the midsouthern (region III). Increasing in RX1day and RX5day may increase the risk of regional floods as these two indices largely represent the intense precipitation events occurring in a very short time [40, 64]. The Jinsha River Basin located in middle-high altitude areas has a high risk of suffering summer flash floods due to extreme precipitation, which often occurs with secondary disasters such as landslides, debris flow, and erosion [65-67]. The JRB is an area of a high incidence of debris flow; about $13 \%$ of debris flow disasters in China occurred here [29]. Since the values of extreme precipitation indices in the JRB were low, their absolute increasing amount was not big. Increase of RX1day in the southeastern and increase of R95p and R10mm in the northwestern were statistically significant $(\alpha=0.05)$. Thus, extreme precipitation in the northeastern (region I) and midnorthern (region II) increased in both the intensity and frequency along with a strong warming trend in temperature extremes [32]. For the midsouthern, extreme precipitation became more frequent as $\mathrm{R} 10 \mathrm{~mm}$ increased in this region. Extreme precipitation increased in intensity but decreased in frequency in the southeastern. General increasing trends of extreme precipitation events in the JRB were also reported in previous studies $[19,33,61]$. Precipitation and snowmelt are the main source of water resource in the Jinsha River Basin. Changes in extreme precipitation may influence water management in this region [68].

All extreme precipitation indices shared a similar spatial pattern with an increasing trend from the northwest to the southeast. The interaction of intricate topography and complicated climate plays an essential role in determining the distribution of extreme precipitation events over this region [69]. Decadal trends of extreme precipitation indices demonstrated large spatial variability across the $\mathrm{JRB}$, but extreme precipitation increased apparently in intensity and frequency in higher elevation areas. The increase in extreme precipitation in higher elevations was due to the cyclonic activity in the north of the Indian subcontinent which brings moisture to the Qinghai-Tibet Plateau combined with the airflow lifted by topography [70]. Recent studies have indicated that changes in extreme precipitation are related to elevation [38, 71]. Spatiotemporal variations of extreme precipitation have critical impacts on ecohydrological processes [72-74]. Therefore, the decision-makers need to realize the spatial heterogeneity and characteristic differences of the extreme precipitation events.
The change point of the extreme precipitation indices in the northwestern mainly occurred in 2007. RX1day abruptly changed in 1978 and RX5day and R95p abruptly changed in 1989 in the midnorthern. The abrupt change points of extreme precipitation indices in the midsouthern and southeastern mainly appeared around 1997 and 2002. Abrupt changes in the 1980s may be related to the change in anomalous water vapors transport over the tropical Indian Ocean-western Pacific in the mid-1980s [75]. Gao et al. indicated that the majority of extreme precipitation indices over monsoon region in China displayed some abrupt shifts in the 1990s which temporally coincided with the abrupt shifts in the El Niño-Southern Oscillation, Indian Ocean Dipole, and Atlantic Multidecadal Oscillation around this period [24]. Xie et al. found that precipitation time series in the central area of southwest China showed an abrupt decrease around 2002-2008, being consistent with the abrupt decrease in 2007 in the Indian summer monsoon [56].

Global extreme precipitation showed a widespread increasing trend and has seriously affected human life and social development [12-14, 36]. However, extreme precipitation events have great regional differences. This study provides a detailed analysis of spatiotemporal variations of extreme precipitation in the JRB. This is very important to study the characteristics of extreme precipitation events in the high mountains of Asia under the background of global climate change. Furthermore, the results can be useful for local government to devise better adaptation and mitigation measures to combat potential catastrophe in changed extreme precipitation.

\section{Data Availability}

The daily precipitation series was provided by China $\mathrm{Me}$ teorological Data Service Center and can be found online at http://data.cma.cn/. Digital Elevation Model data were downloaded from the Geospatial Data Cloud of China and accessed via http://www.gscloud.cn/.

\section{Conflicts of Interest}

The authors declare that there are no conflicts of interest regarding the publication of this paper.

\section{Acknowledgments}

This study was funded by the National Science Foundation Committee of China (no. 51679155).

\section{References}

[1] A. K. Knapp, C. Beier, D. D. Briske et al., "Consequences of more extreme precipitation regimes for terrestrial ecosystems," Bioscience, vol. 58, no. 9, pp. 811-821, 2008.

[2] M. R. Classen and W. J. Ingram, "Constraints on future changes in climate and the hydrologic cycle," Nature, vol. 419, no. 6903 , p. 224, 2002.

[3] R. Dankers and L. Feyen, "Climate change impact on flood hazard in Europe: an assessment based on high-resolution climate simulations," Journal of Geophysical Research-Atmospheres, vol. 113, no. D19, 2008. 
[4] S. Pfahl, P. A. O'Gorman, and E. M. Fischer, "Understanding the regional pattern of projected future changes in extreme precipitation," Nature Climate Change, vol. 7, no. 6, pp. 423-427, 2017.

[5] Q. Zhang, C.-Y. Xu, Y. D. Chen, and T. Yang, "Spatial assessment of hydrologic alteration across the Pearl River Delta, China, and possible underlying causes," Hydrological Processes, vol. 23, no. 11, pp. 1565-1574, 2009.

[6] I. F. A. Cavalcanti, "Large scale and synoptic features associated with extreme precipitation over South America: a review and case studies for the first decade of the 21st century," Atmospheric Research, vol. 118, pp. 27-40, 2012.

[7] J. P. Powell and S. Reinhard, "Measuring the effects of extreme weather events on yields," Weather and Climate Extremes, vol. 12, pp. 69-79, 2016.

[8] Z. Li, W.-Z. Liu, X.-C. Zhang et al., "Assessing the site-specific impacts of climate change on hydrology, soil erosion and crop yields in the Loess Plateau of China," Climatic Change, vol. 105, no. 1-2, pp. 223-242, 2011.

[9] C. Jiang, K. S. Shaw, C. R. Upperman et al., "Climate change, extreme events and increased risk of salmonellosis in Maryland, USA: evidence for coastal vulnerability," Environment International, vol. 83, pp. 58-62, 2015.

[10] Y. Blythe, W. Wang, N. Zhang, J. K. Yan, and Y. Wei, "The June 2017 Maoxian landslide: geological disaster in an earthquake area after the Wenchuan Ms 8.0 earthquake," Science China Technological Sciences, vol. 60, no. 11, pp. 1762-1766, 2017.

[11] X. Yan, Q. Xu, G. Scaringi et al., "Failure mechanism and kinematics of the deadly June 24th 2017 Xinmo landslide, Maoxian, Sichuan, China," Landslides, vol. 14, no. 6, pp. 2129-2146, 2017.

[12] L. V. Dai, X. Zhang, T. C. Peterson et al., "Global observed changes in daily climate extremes of temperature and precipitation," Journal of Geophysical Research-Atmospheres, vol. 111, no. D5, 2006.

[13] M. L. Griffiths and R. S. Bradley, "Variations of twentiethcentury temperature and precipitation extreme indicators in the northeast United States," Journal of Climate, vol. 20, no. 21, pp. 5401-5417, 2007.

[14] T. A. Cinco, R. G. de Guzman, F. D. Hilario, and D. M. Wilson, "Long-term trends and extremes in observed daily precipitation and near surface air temperature in the Philippines for the period 1951-2010," Atmospheric Research, vol. 145-146, pp. 12-26, 2014.

[15] C. V. Wilson, A. Dharma Raju, G. C. Satyanarayana, P. Vinay Kumar, G. Chiranjeevi, and P. Suchitra, "An observational evidence of decrease in Indian summer monsoon rainfall in the recent three decades of global warming era," Global and Planetary Change, vol. 127, pp. 91-102, 2015.

[16] N. Vinay Kumar, S. S. Singh, and N. Priya, "Extreme rainfall indices and its impact on rice productivity-a case study over sub-humid climatic environment," Agricultural Water Management, vol. 98, no. 9, pp. 1373-1387, 2011.

[17] P. P. Jena, C. Chatterjee, and G. Pradhan, "Are recent frequent high floods in Mahanadi basin in eastern India due to increase in extreme rainfalls?" Journal of Hydrology, vol. 517, pp. 847-862, 2014.

[18] M. Mishra and S. Saeed, "Contribution of extreme daily precipitation to total rainfall over the Arabian Peninsula," Atmospheric Research, vol. 231, 2020.

[19] P. Zhai, X. Zhang, H. Wan, and X. Pan, "Trends in total precipitation and frequency of daily precipitation extremes over China," Journal of Climate, vol. 18, no. 7, pp. 1096-1108, 2005.
[20] C. Pan, Y. Luo, and Y. Xu, "Projected changes of precipitation extremes in river basins over China," Quaternary International, vol. 244, no. 2, pp. 149-158, 2011.

[21] Y. Q. Wang and L. Zhou, "Observed trends in extreme precipitation events in China during 1961-2001 and the associated changes in large-scale circulation," Geophysical Research Letters, vol. 32, no. 9, 2005.

[22] K. Sedlmeier, H. Feldmann, and G. Schaedler, "Compound summer temperature and precipitation extremes over central Europe," Theoretical and Applied Climatology, vol. 131, no. 34, pp. 1493-1501, 2018.

[23] X. Li, X. Wang, and V. Babovic, "Analysis of variability and trends of precipitation extremes in Singapore during 1980-2013," International Journal of Climatology, vol. 38, no. 1, pp. 125-141, 2018.

[24] T. Gao, H. J. Wang, and T. Zhou, "Changes of extreme precipitation and nonlinear influence of climate variables over monsoon region in China," Atmospheric Research, vol. 197, pp. 379-389, 2017.

[25] M. X. Liu, X. L. Xu, A. Y. Sun et al., "Is southwestern China experiencing more frequent precipitation extremes?" Environmental Research Letters, vol. 9, no. 6, 2014.

[26] J.-L. Zhou, Q.-Q. Xu, and X.-Y. Zhang, "Water resources and Sustainability assessment based on group AHP-PCA method: a case study in the Jinsha River basin," Water, vol. 1012 pages, 2018.

[27] Z. Yuan, J. Xu, and Y. Wang, "Projection of future extreme precipitation and flood changes of the Jinsha River basin in China based on CMIP5 climate models," International Journal of Environmental Research and Public Health, vol. 15, no. 11, 2018.

[28] J. Fluixá-Sanmartín, D. Pan, L. Fischer et al., "Searching for the optimal drought index and timescale combination to detect drought: a case study from the lower Jinsha River basin, China," Hydrology and Earth System Sciences, vol. 22, no. 1, pp. 889-910, 2018.

[29] D. Orlowsky, H. Xie, and F. Wei, Comprehensive Regionalization of Debris Flow Risk Degree in the Upper Yangtze River, Scientific and Technical Publishers, Shanghai, China, 2010, in Chinese.

[30] S. Wang, X. Zhang, Z. Liu, and D. Wang, "Trend analysis of precipitation in the Jinsha River basin in China," Journal of Hydrometeorology, vol. 14, no. 1, pp. 290-303, 2013.

[31] S. J. Wang and X. L. Zhang, "Long-term trend analysis for temperature in the Jinsha River basin in China," Theoretical and Applied Climatology, vol. 109, no. 3-4, pp. 591-603, 2012.

[32] L. F. Cui, L. C. Wang, S. Qu et al., "Spatiotemporal extremes of temperature and precipitation during 1960-2015 in the Yangtze River basin (China) and impacts on vegetation dynamics," Theoretical and Applied Climatology, vol. 136, no. 12, pp. 675-692, 2019.

[33] B. Su, M. Gemmer, and T. Jiang, "Spatial and temporal variation of extreme precipitation over the Yangtze River basin," Quaternary International, vol. 186, no. 1, pp. 22-31, 2008.

[34] S. Das, D. Zhu, and C.-H. Cheng, "A regional approach of decadal assessment of extreme precipitation estimates: a case study in the Yangtze River basin, China," Pure and Applied Geophysics, vol. 177, no. 2, pp. 1079-1093, 2020.

[35] Q. You, S. Kang, E. Aguilar et al., "Changes in daily climate extremes in China and their connection to the large scale atmospheric circulation during 1961-2003," Climate Dynamics, vol. 36, no. 11-12, pp. 2399-2417, 2011. 
[36] P. Frich, L. Alexander, P. Della-Marta et al., "Observed coherent changes in climatic extremes during the second half of the twentieth century," Climate Research, vol. 19, no. 3, pp. 193-212, 2002.

[37] M. G. Gleason, L. V. Alexander, H. Yang et al., "Updated analyses of temperature and precipitation extreme indices since the beginning of the twentieth century: the HadEX2 dataset," Journal of Geophysical Research: Atmospheres, vol. 118, no. 5, pp. 2098-2118, 2013.

[38] C. Mei, J. Liu, M.-T. Chen, H. Wang, M. Li, and Y. Yu, "Multidecadal spatial and temporal changes of extreme precipitation patterns in northern China (Jing-Jin-Ji district, 1960-2013)," Quaternary International, vol. 476, pp. 1-13, 2018.

[39] Z. Wang, "Annual daily maximum rainfall-based IDF curve derivation methodology," Earth Systems and Environment, vol. 3, no. 3, pp. 463-469, 2019.

[40] G. Zhao, X. Mu, G. Hörmann et al., "Spatial patterns and temporal variability of dryness/wetness in the Yangtze River basin, China," Quaternary International, vol. 282, pp. 5-13, 2012.

[41] E. N. Fohrer, Empirical Orthogonal Functions and Statistical Weather Prediction, Massachusetts Institute of Technology, Department of Meteorology, Cambridge, MA, USA, 1956.

[42] M. Hatzaki and R. Wu, "The south-eastern Europe winter precipitation variability in relation to the North Atlantic SST," Atmospheric Research, vol. 152, pp. 61-68, 2015.

[43] H. F. Kaiser, "The varimax criterion for analytic rotation in factor analysis," Psychometrika, vol. 23, no. 3, pp. 187-200, 1958.

[44] M. B. Richman, "Rotation of principal components," Journal of Climatology, vol. 6, no. 3, pp. 293-335, 1986.

[45] K.-Y. Kim and Q. Wu, "A comparison study of EOF techniques: analysis of nonstationary data with periodic statistics," Journal of Climate, vol. 12, no. 1, pp. 185-199, 1999.

[46] H. B. Mann, "Nonparametric tests against trend," Econometrica, vol. 13, no. 3, pp. 245-259, 1945.

[47] M. G. Kendall, Rank Correlation Methods, Charles Graffin, London, UK, 1975.

[48] R. M. da Silva, C. A. G. Santos, M. Moreira, J. Corte-Real, V. C. L. Silva, and I. C. Medeiros, "Rainfall and river flow trends using Mann-Kendall and Sen's slope estimator statistical tests in the Cobres River basin," Natural Hazards, vol. 77, no. 2, pp. 1205-1221, 2015.

[49] R. Corte-Real and M. Dawood, "Spatio-statistical analysis of temperature fluctuation using Mann-Kendall and Sen's slope approach," Climate Dynamics, vol. 48, no. 3-4, pp. 783-797, 2017.

[50] S. Yue, P. Pilon, B. Phinney, and G. Cavadias, "The influence of autocorrelation on the ability to detect trend in hydrological series," Hydrological Processes, vol. 16, no. 9, pp. 1807-1829, 2002.

[51] I. Cavadias, D. Tang, T. Wang et al., "Precipitation trends over time using Mann-Kendall and Spearman's rho tests in Swat River basin, Pakistan," Advances in Meteorology, vol. 2015, Article ID 431860, 2015.

[52] P. K. Sen, "Estimates of the regression coefficient based on Kendall's tau," Journal of the American Statistical Association, vol. 63, no. 324, pp. 1379-1389, 1968.

[53] H. Theil, "A rank-invariant method of linear and polynomial regression analysis," Proceedings of Koninalijke Nederlandse Akademie Van Weinenschatpen A, vol. 53, pp. 1397-1412, 1950.

[54] S. Subba, Y. Ma, and W. Ma, "Spatial and temporal analysis of precipitation extremities of eastern Nepal in the last two decades (1997-2016)," Journal of Geophysical Research: Atmospheres, vol. 124, no. 14, pp. 7523-7539, 2019.

[55] A. Tarhule and M.-K. Woo, "Changes in rainfall characteristics in northern Nigeria," International Journal of Climatology, vol. 18, no. 11, pp. 1261-1271, 1998.

[56] P. Xie, H. T. Gu, Y. F. Sang et al., "Comparison of different methods for detecting change points in hydroclimatic time series," Journal of Hydrology, vol. 577, p. 11, 2019.

[57] J. Ding, "Statistical detection for transition point in flood time sequences," Engineering Journal of Wuhan University, vol. 5, pp. 36-41, 1986, in Chinese.

[58] A. N. Pettitt, "A non-parametric approach to the changepoint problem," Applied Statistics, vol. 28, no. 2, pp. 126-135, 1979.

[59] L. Liang, L. Li, and Q. Liu, "Precipitation variability in northeast China from 1961 to 2008," Journal of Hydrology, vol. 404, no. 1-2, pp. 67-76, 2011.

[60] R. B. Cattell, "The scree test for the number of factors," Multivariate Behavioral Research, vol. 1, no. 2, pp. 245-276, 1966.

[61] Q. H. Chen, H. Chen, J. X. Wang et al., "Impacts of climate change and land-use change on hydrological extremes in the Jinsha River basin," Water, vol. 11, no. 7, p. 25, 2019.

[62] S. K. Lee and T. A. Dang, "Extreme rainfall trends over the Mekong delta under the impacts of climate change," International Journal of Climate Change Strategies and Management, vol. 14, 2020.

[63] C. Xu, N. G. McDowell, R. A. Fisher et al., "Increasing impacts of extreme droughts on vegetation productivity under climate change," Nature Climate Change, vol. 9, no. 12, p. 948, 2019.

[64] Y. Wei and P. M. Zhai, "Persistent extreme precipitation events in China during 1951-2010," Climate Research, vol. 57, no. 2, pp. 143-155, 2013.

[65] Y. Y. Wu, H. W. Fang, L. Huang et al., "Changing runoff due to temperature and precipitation variations in the dammed Jinsha River," Journal of Hydrology, vol. 582, p. 12, 2020.

[66] X. H. Sun, J. P. Chen, Y. D. Bao et al., "Flash flood schlep ability estimation in vertical distribution law of the precipitation area: a case of Xulong gully, Southwest China," Arabian Journal of Geosciences, vol. 12, no. 9, 2019.

[67] Fauna, "China Battling Floods \& Droughts, 2010 Chinese News Photos," 2010, https://www.chinasmack.com/battlingfloods-droughts-2010-chinese-news-photos.

[68] S. Zhu, Z. Y. Xu, X. G. Luo et al., "Assessing coincidence probability for extreme precipitation events in the Jinsha River basin," Theoretical and Applied Climatology, vol. 139, no. $1-2$, pp. 825-835, 2020.

[69] T. Gao and L. A. Xie, "Study on progress of the trends and physical causes of extreme precipitation in China during the last 50 years," Advances in Earth Science, vol. 29, no. 5, pp. 577-589, 2014, in Chinese.

[70] Z. X. Li, Y. Q. He, P. Y. Wang et al., "Changes of daily climate extremes in southwestern China during 1961-2008," Global and Planetary Change, vol. 80-81, pp. 255-272, 2012.

[71] F. Chen, H. Chen, and Y. Yang, "Annual and seasonal changes in means and extreme events of precipitation and their connection to elevation over Yunnan province, China," Quaternary International, vol. 374, pp. 46-61, 2015.

[72] E. P. Hamerlynck, R. L. Scott, and J. J. Stone, "Soil moisture and ecosystem function responses of desert grassland varying in vegetative cover to a saturating precipitation pulse," Ecohydrology, vol. 5, no. 3, pp. 297-305, 2012.

[73] X. Wang, X. Yang, T. Liu et al., "Trend and extreme occurrence of precipitation in a mid-latitude Eurasian steppe 
watershed at various time scales," Hydrological Processes, vol. 28, no. 22, pp. 5547-5560, 2014.

[74] A. L. A. Li, G. R. Liska, L. A. Beijo et al., "Generalized Pareto distribution applied to the analysis of maximum rainfall events in Uruguaiana, RS, Brazil," SN Applied Sciences, vol. 2, no. 9, p. 13, 2020.

[75] M. Zou, S. Qiao, T. Feng, Y. Wu, and G. Feng, "The interdecadal change in anomalous summertime water vapour transport modes over the tropical Indian Ocean-western Pacific in the mid-1980s," International Journal of Climatology, vol. 38, no. 6, pp. 2672-2685, 2018. 